Гуманитарные ведомости ТГПУ им. Л. Н. Толстого № 4 (36), декабрь 2020 г.

ДУИН

Белгородский государственный национальный исследовательский университет

HACY

Белгородский государственный национальный исследовательский университет

\title{
МУЗЫКА КАК ПРАКТИЧЕСКАЯ И ДУХОВНАЯ ЦЕННОСТЬ
}

В статье реализовано культурологическое осмысление некоторых
парадоксов вхождения китайских детей в современную музыкальноисполнительскую культуру, в связи с чем рассматриваются социальные и культурные факторы, приводящие к негативной тенденции в музыкальной сфере. Отмечается, что процесс музыкального образования все в большей степени становится утилитарно направленным и чрезмерно рациональным, а его художественная ценность отодвигается на периферию понимания музыки как духовной и практической ценности нации. При этом трансформируется сущность музыкального образования. Эти проблемные зоны составляют предметное поле авторского исследования.

Ключевые слова: китайская система музыкального образования, музыкально-исполнительская культура, музыкальные инструменты, художественная ценность, соцокультурные факторы.

DUIN

Belgorod State National Research University

(Belgorod, Russia)

NASU

Belgorod State National Research University

(Belgorod, Russia)

\section{MUSIC AS A PRACTICAL AND SPIRITUAL VALUE}

The article implements a cultural understanding of some of the paradoxes of the entry of Chinese children into the modern musical and performing culture. In connection with this, the authors consider the social and cultural factors leading to a negative trend in the musical sphere. The work notes that the process of music education is increasingly becoming utilitarian and excessively rational, and its artistic value is being pushed to the periphery of understanding music as a spiritual and practical value of the nation. At the same time, the essence of music education is transformed. These problem areas constitute the subject field of the authors' research.

Keywords: Chinese system of music education, musical and performing culture, musical instruments, artistic value, social and cultural factors.

\section{DOI 10.22405/2304-4772-2020-1-4-133-139}

Мы используем собственный музыкально-педагогический опыт, так как некоторое время были практикующими педагогами по классу «фортепиано» в Детском учебном центре Хулунбел (город в автономной области Внутренней Монголии), в силу чего выявили некоторые проблемы «изнутри». В частности, противоречие между утилитарной ориентацией музыкальногообразовательного процесса в современных музыкальных учреждениях КНР с 
Гуманитарные ведомости ТГПУ им. Л. Н. Толстого № 4 (36), декабрь 2020 г.

одной стороны, и художественной ценностью «воспитания музыкой», восходящей к культурной традиции Древнего Китая, с другой. Мы постараемся осмыслить данную тенденцию с точки зрения аксиологической значимости художественного творчества как универсальной культурной практики.

В данном контексте мы сразу же перейдем к проблемным вопросам, связанным с несовершенной, как нам представляется, системой музыкального обучения детей в Китае. Одновременно укажем на специфику китайского музыкального обучения. Она, во-первых, связана с отношением к музыке как к национальной ценности: эта парадигма, в основе которой лежит принцип «уважения к древности», культивируемая на протяжении всей китайской истории, и которая сохраняется на государственном уровне в условиях «нового Китая». Во-вторых, вся музыкальная подготовка китайских музыкантов попрежнему устойчиво базируется на первичном звене, которое составляет семейное «воспитание музыкой». Разумеется, присутствуют и другие характерные особенности овладения китайской молодежью основами музыкально-исполнительской культуры.

В настоящий момент ситуация такова, что многие родители в Китае, чтобы выяснить интерес своего ребенка к тому или иному музыкальному инструменту, в очень раннем возрасте (как правило, в возрасте 4-6 лет), отдают детей в музыкальные учебные заведении за пределами «обычной» школы. При этом сразу же стоит задача выбора наиболее предпочтительного музыкального инструмента для обучения ребенка игре на нем, в связи с чем обязательным является предварительная консультация с учителем конкретного музыкального заведения. К сожалению, не многие из будущих учеников действительно заинтересованы в инструментах, которые они выбирают и действительно хотят учиться музыке. Как правило (это показывает практика нашей собственной работы с таким контингентом), большинство детей, осуществляя выбор инструмента, проявляют не более чем «простое» сиюминутное любопытство, что вполне естественно для их раннего возраста. Кроме того, как показывает та же практика, часто выбор инструмента - вынужденное явление, поскольку происходит это или по просьбе родителей, или под их давлением.

Разумеется, при этом решающем является рекомендация музыкального педагога, которая, надо полагать, нисколько не идет в разрез с желанием родителя (а шире - семьи). И на то есть своя причина, обусловленная достаточно часто меркантильным, прагматичным фактором, в рамках которого педагог напрямую заинтересован в количественной наполняемости и комплектации собственного контингента учеников. Как говорится, материальный интерес и сегодня остается двигателем прогресса в условиях рыночной экономики [12, с. 125].

В настоящее время существует достаточно большое количество научных исследований по проблеме музыкального образования детей в КНР. При этом выясняется, что интерес родителей дать своим детям музыкальное образование не однозначен. Одна часть искреннее руководствуется склонностью ребенка, видя, что их ребенок действительно проявляет подлинный интерес к музыке, к 
Гуманитарные ведомости ТГПУ им. Л. Н. Толстого № 4 (36), декабрь 2020 г.

игре на выбранном им музыкальном инструменте. Прилагают усилия, чтобы он повышал свое мастерство, и при наличии явно проявляющейся одаренности стремятся дать сыну или дочери настоящее музыкальное образование, сделав его первой ступенью профессиональной музыкальной лестницы [10, с. 101]. Другая часть родителей стремится дать ребенку музыкальное образование из престижных соображений.

Корни воспитания человека посредством музыки уходят далеко в историю Древнего Китая, правители которого считали этот вопрос вопросом государственной политики [8; 9]. Несомненно, музыка играла немалую роль в развитии государства. Ведь выходцы из средних слоев, самостоятельно овладевавшие этими двумя условиями приема на государственную службу, были, несомненно, способными (возможно, и талантливыми) людьми, целеустремленными, прилагающими усилия для того, чтобы на конкурсных условиях получить место в государственной структуре $[9$, с. 303]. В подтверждение своей мысли обратимся к следующему фрагменту из Лунь Юй Беседы и суждения, одному из важнейших источников конфуцианства: «Учитель сказал: «Те, кто сначала изучал «Правила» и музыку, а потом становились чиновниками - обычные люди, не имевшие рангов и жалований. Те, которые сначала становились чиновникам и лишь потом изучали Правила и музыку, дети цинов и дафу. Если бы мне понадобились способные, то я выбрал бы из тех, кто начал с изучения (цины и дафу - аристократия)» [4].

Следует сказать, что в значительной части китайских школ академические занятия музыкой (поурочная система) являются малоэффективными для достижения качественной «музыкальной образованности» (один час музыки в неделю явно не достаточен). Во многом это, по нашим личным наблюдениям, является первопричиной низкого уровня знаний учащихся по этому предмету. Не секрет, что некоторые учителя музыки, чтобы улучшить успеваемость своих обучаемых, прибегают к практике так называемых уроков музыкального самообучения. Собственно, это говорит о том, что обучающимся в данных музыкальных учебных заведениях трудно, а порой практически невозможно получить полноценное и качественное музыкальное образование. Такое положение привело уже сегодня к тому, что традиционная система музыкального образования на школьном этапе не может удовлетворить потребности родителей, а также и тех учащихся, которые хотят серьезно изучать музыку, думают о продолжении обучения в профильных музыкальных учебных заведениях.

Сложившуюся на сегодняшний день в Китае модель массового музыкального образования отягощает, на наш взгляд, тот факт, что не достаточная роль отводится пониманию значимости такого компонента музыкальной исполнительской культуры, как уровень импровизации в исполнении музыкального произведения. А ведь именно мастерство импровизации поднимает музыканта к вершинам исполнительства, наполняющим произведение высоким духовным содержанием, когда музыка благотворным образом воздействует на духовную сферу человека. Сошлемся, в 
Гуманитарные ведомости ТГПУ им. Л. Н. Толстого № 4 (36), декабрь 2020 г.

частности, на М. И. Бенюмова, который отмечает: «Процесс творчества превращается в своеобразный диалог творца с создаваемой им художественной конструкцией. Сравнивая реальные впечатления с замыслом и фиксируя возникающие несовпадения, художник уточняет не только материальную форму, но и (что особенно важно) внутреннее видение. Его фантазия питается импульсами, идущими от восприятия, от живых, непосредственных впечатлений» [5, с. 22].

Рефлексия феномена музыкального образования и воспитания с точки зрения его ценности показывает, что наблюдающаяся сегодня утилитарная ориентация преподавания в китайских музыкальных учреждениях становится все более серьезной, что его художественная направленность теряет свою первоначальную привлекательность. Дети, музыкальное обучение которых направлено на совершенствование игрового исполнительства (быстрота пальцев и т.п.), не могут оценить реальную художественную ценность произведения, его идейную тематику, его гуманистическую направленность на чувства и слушателя, и самого исполнителя [см.: 13, с. 4-5].

С учетом сказанного, мы приходим к обобщению, что в современном китайском обществе в условиях социальных и культурных трансформаций и под объективным влиянием мировых интеграционных процессов музыкальное образование все более становится утилитарным, начиная уже с первичной стадии семейного обучения. Одновременно его художественный потенциал слабеет. По этой причине происходит подмена аксиологии музыкального образования ее симулякром, «настоящего искусства» псевдоискусством. Музыка становится высоко рейтинговым «культурным товаром», а то и хорошо раскрученным брендом. Все это размывает ценность художественного творчества как такового, не позволяет в полной мере начинающим юным музыкантам по-настоящему оценить очарование искусства.

Мы полагаем, что в настоящее время в КНР обозначилась тенденция, отдающая приоритеты рационально-утилитарному подходу в сфере музыкально-образовательной культуры. И это понятно: сегодня в КНР в рамках стратегического курса и политики «культурной индустрии» большое внимание уделяется процессам рыночных механизмов в сфере производства культуры. Провозглашается, что именно такие механизмы должны стать «основной силой в распределении культурных источников, в строительстве макросистем управления культурой, в сферах производства культуры и услуг, имеющих высокую эффективность» [2, с. 29]. То есть, речь идет о «воспитании субъекта культурного рынка нового типа, который станет основной силой развития культурной индустрии, субъектом инноваций в культуре $[7 ; 10 ; 11]$.

Однако, нужно учитывать, что в ряду основных принципов китайской культуры, в том числе и культуры музыкального исполнительства находится установка, суть которой выражает формула: «Видеть идеал в древности». Отсюда основным оценочным критерием «правильности» всякой деятельности (вне зависимости от сферы приложения) является показатель и критерий ее древности. Данный принцип, во-первых, положен в основание традиционной и 
Гуманитарные ведомости ТГПУ им. Л. Н. Толстого № 4 (36), декабрь 2020 г.

современной китайской культуры. Во-вторых, он отражает главную культурную установку: отношение в китайском обществе к музыкальной сфере как к национальной духовной и практической ценности. В-третьих, данная культурная парадигма, уходя своей «корневой системой» в структуру древнекитайского государства носит универсальный характер.

Данная культурная парадигма, сохраняя свою роль и значимость в современной КНР, является характерным примером модернизации великой национальной культуры на всех государственных уровнях. Традиция, бережно сохраняясь и приумножаясь, выступает хорошим стимулом в культурноидеологическом курсе страны на взятие мировых вершин в сфере китайского исполнительства.

\section{Лumepamypa}

1. Бенюмов М. И. О понятии музыкального исполнения. Красноярск, 1981. 51 с. Деп. в НИО Информ. Гос. б-ки СССР им. В.И. Ленина 21.07.81; № 191.

2. Культура в условиях глобализации. Взгляд из России: монография / под ред. А. Н. Чумакова. М.: КноРус, 2017. 371 с.

3. Лин Цянсань. Исследование восточноазиатских музыкальных инструментов. Пекин: Нар. муз. изд-во, 1962.

4. Лунь Юй. Гл. 1-9, 11-17, 20 / пер. В. А. Кривцова // Древнекитайская философия. Т. 1. М., 1973.

5. Музыкальное исполнение: логика понятия и историческая эволюция // Культура. Искусство. Образование: межвуз. сб. Вып. 9. Красноярск, 2010. С. 25-44.

6. Народная музыкальная культура русской провинции: проблемы сохранения и развития: сборник докладов международной научнопрактической конференции (в рамках VIII научно-творческих «Маничкиных чтений», Белгород, 21-22 марта 2019 г.). Белгород, БГИИК, 2019. С. 238-241.

7. О различиях стратегической и функциональной политики // Введение в анализ государственной политики. Пекин: Изд-во Китайского нар. ун-та, 2014. С. 162-166.

8. Позднеев А. М. Образцы народной литературы монгольских племен. Народные песни монголов. Вып. 1. СПб., 1880. 346 с.

9. Позднеев А. М. Очерки быта буддийских монастырей и буддийского духовенства в Монголии. СПб., 1887. 494 с.

10. Тульчинский Г. Фандрейзинг: привлечение средств на проекты и программы в сфере культуры и образования. СПб.: Лань, 2010. 286 с.

11. Цзя Сюйдун. Культурная политика и индустрия Китая в контексте глобализации // Век глобализации. 2018. № 2. С. 111-114.

12. Чжон Ши-бин, Гон Чжэн. Анализ западного м музыкального образования. Шанхай, 2007. 372 с.

13. Чжэн Бин-и. Историческая концепция китайской музыки. Чжон Чин, 2007. 354 с. 
Гуманитарные ведомости ТГПУ им. Л. Н. Толстого № 4 (36), декабрь 2020 г.

14. Ян Бо. Динамика развития профессионального сольного пения в Китае: образование, педагогические и исполнительские принципы : дис. ... канд. искусствовед. : 17.00.02 / Ян Бо. Нижний Новгород, 2016. 186 с.

\section{References}

1. Benyumov M. I. O ponyatii muzykal'nogo ispolneniya [On the concept of musical performance]. Krasnoyarsk, 1981. 51 p. (Manuscript of the Department in the research Institute of information of the state. b-Ki USSR named after V. I. Lenin 21. 07. 81; No. 191). [In Russian]

2. Kul'tura $\mathrm{v}$ usloviyakh globalizatsii. Vzglyad iz Rossii: monografiya [Globalization from a Philosophical Point of View: Russian Vision]. Ed. by Chumakov A. N. Moscow: KnoRus Publ., 2017. 371 p. [In Russian]

3. Lin Qiangsan. Issledovaniye vostochno-aziatskikh muzykal'nykh instrumentov [Study of East Asian Musical Instruments]. Beijing: People's Music Publishing House, 1962. [In Russian]

4. Lun' Yuy [Lunyu] Drevnekitayskaya filosofiya [Ancient Chinese philosophy]. Vol. 1. CH. 1-9, 11-17, 20. Transl. by V. A. Krivtsov. Moscow: 1973. [In Russian]

5. Muzykal'noye ispolneniye: logika ponyatiya i istoricheskaya evolyutsiya [Musical Performance: Logic of Concept and Historical Evolution]. Kul'tura. Iskusstvo. Obrazovaniye: sb. nauch. i metod. trudov [Culture. Art. Education: Intercollegiate Collection of Scientific and Methodological Works]. Issue 9. Krasnoyarsk: 2010. P. 25-44. [In Russian]

6. Narodnaya muzykal'naya kul'tura russkoy provintsii: problemy sokhraneniya i razvitiya: sb. dokl. mezhdunar. nauch.-prakt. konf. (v ramkakh VIII nauchno-tvorcheskikh «Manichkinykh chteniy», Belgorod, 21-22 Marta 2019 g.) [Folk music culture of the Russian province: problems of preservation and development: collection of reports of the international scientific and practical conference (within the VIII scientific and creative "Manichkin readings", Belgorod, March 21-22, 2019)]. Belgorod: BGIIK Publ., 2019. Pp. 238-241. [In Russian]

7. O razlichiyakh strategicheskoy i funktsional'noy politiki [On the differences between strategic and functional policy] Vvedeniye $\mathrm{v}$ analiz gosudarstvennoy politiki [Introduction to the analysis of public policy]. Beijing: Publishing House of the Chinese People's University, 2014. Pp. 162-166. [In Russian]

8. Pozdneev A. M. Obraztsy narodnoy literatury mongol'skikh plemen. Narodnyye pesni mongolov [Samples of folk literature of the Mongolian tribes. Mongolian Folk Songs]. Vol 1. St. Petersburg, 1880. 346 p. [In Russian]

9. Pozdneev A. M. Ocherki byta buddiyskikh monastyrey i buddiyskogo dukhovenstva v Mongolii [Essays on the life of Buddhist monasteries and Buddhist clergy in Mongolia]. St. Petersburg, 1887. 494 p. [In Russian]

10. Tul'chinski G. L. Fandreyzing: Privlechenie sredstv na proekty i programmy $\mathrm{v}$ sfere kultury i obrazovaniya [Fundraising: Raising funds for projects 
Гуманитарные ведомости ТГПУ им. Л. Н. Толстого № 4 (36), декабрь 2020 г.

programs in field culture education]. St. Petersburg: Lan Publ., 2010. 286 p. [In Russian]

11. Jia Xudong Kul'turnaya politika $\mathrm{i}$ industriya Kitaya $\mathrm{v}$ kontekste globalizatsii [China's Cultural Policy and Industry in the Context of Globalization]. Vek Globalizatsii [Age of Globalization], 2018, Issue. 2 (26), pp. 101-114. [In Russian]

12. Jung Shi-bin, Gong Zheng Analiz zapadnogo muzykal'nogo obrazovaniya [Analysis of Western Music Education]. Shanghai, 2007.372 p.

13. Zheng Bing-yi. Istoricheskaya kontseptsiya kitayskoy muzyki [Historical concept of Chinese music]. Jung Chin, 2007.354 p.

14. Yang Bo. Dinamika razvitiya professional'nogo sol'nogo peniya v Kitaye: obrazovaniye, pedagogicheskiye i ispolnitel'skiye printsipy [Development Dynamics of Professional Singing in China: Education, Pedagogical and Performing Principles] diss. ... kand. iskusstvoved. nauk [Thes. ... Cand. Apт History Sciences] : 17.00.02. Nizhny Novgorod, 2016.186 p. [In Russian]

Статья поступила в редакиию 12.11.2020

Статья допущена к публикащии 14.12.2020

The article was received by the editorial staff 12.11.2020

The article is approved for publication 14.12.2020 